\begin{tabular}{|l|c|c|}
\hline Q19. & \multicolumn{3}{|c|}{$\begin{array}{c}\text { Eurasian Academy of Sciences } \\
\text { Eurasian Education \& Literature Journal } \\
\text { Volume:1 }\end{array}$} & S: $59-67$ \\
\hline
\end{tabular}

\title{
THE VALIDITY AND RELIABILITY OF THE TURKISH VERSION OF ADOLESCENT SELF-EFFICACY SCALE FOR SEXUAL ABSTINENCE
}

\section{Eyüp Çelik*; Mehmet Emin Turan **}

Sakarya Üniversitesi*; Milli Eğitim Bakanlığı $* *$

E-mail: eyupcpdr@hotmail.com*; mehmeteminturan@gmail.com**

Copyright (C) 2015 Eyüp Çelik; Mehmet Emin Turan. This is an open access article distributed under the Eurasian Academy of Sciences License, which permits unrestricted use, distribution, and reproduction in any medium, provided the original work is properly cited.

\begin{abstract}
Aim of the present study was to examine validity and reliability of the Turkish version of adolescent self-efficacy scale for sexual abstinence. The results of exploratory factor analysis demonstrated that nine items loaded on single-factors, and that the factor structure was harmonized with the factor structure of the original scale. Confirmatory factor analysis showed that chi-square $(\chi 2=95.34, \mathrm{DF}=26, \mathrm{p}=0.00)$ and fit indices (RMSEA $=.084$, GFI $=$ $.95, \mathrm{AGFI}=.91, \mathrm{CFI}=.97, \mathrm{IFI}=.97, \mathrm{NFI}=.95, \mathrm{RFI}=.94$, and $\mathrm{SRMR}=.03)$ was acceptable. Cronbach's alpha was found as .91. Item analysis showed that t-test results was significant, and also corrected item-total correlations was ranged from .47 to .76 . According to the present study findings, we can say that the scale is a valid and reliable instrument.
\end{abstract}

Keywords: self-efficacy for sexual abstinence, exploratory factor analysis, confirmatory factor analysis

\section{Ergenler İçin Cinsel Kaçınmada Öz-Yeterlik Ölçeği’nin Türkçe Formunun Geçerlik ve Güvenirliği}

ÖZET: Araştırmanın amacı, ergenler için Cinsel Kaçınmada Öz-yeterlik Ölçeği'ni Türkçeye uyarlamak ve psikometrik özelliklerini incelemektir. Açımlayıcı faktör analizi sonucu ölçeğin dokuz maddeli orijinal formuna uygun tek faktörlü bir yapıya sahip ollduğu bulunmuştur. Yapılan doğrulayıcı faktör analizinde Ki-kare değerinin $(\chi 2=95.34, \mathrm{SD}=26, \mathrm{p}=0.00)$ ve uyum indekslerinin $(\mathrm{RMSEA}=.084, \mathrm{GFI}=.95, \mathrm{AGFI}=.91, \mathrm{CFI}=.97, \mathrm{IFI}=.97, \mathrm{NFI}=.95$, $\mathrm{RFI}=.94$ ve $\mathrm{SRMR}=.03) \mathrm{kabul}$ edilebilir düzeyde olduğu görülmüştür. Ölçeğin güvenirlik analizi sonucu Cronbach Alfa güvenirlik katsayısı .91 olarak bulunmuştur. Madde analizi için yapılan analizde t-testi sonuçlarının anlamlı ve düzeltilmiş madde-test korelasyonlarının .47 ile .76 arasında sonucuna ulaşılmıştır. Yapılan analizler sonucu elde edilen bu sonuçlar ölçeğin geçerli ve güvenilir bir ölçme aracı olduğunu göstermektedir. 
Anahtar Kelimeler: cinsel kaçınmada öz-yeterlilik, açımlayıcı faktör analizi, doğrulayıcı faktör analizi

\section{GİRIŞ}

Ergenlik dönemi, çocukluktan yetişkinliğe geçiş sürecini kapsayan ve birçok değişimlerin yaşandığ1 önemli bir gelişim dönemi olduğu düşünülebilir. Bu dönemde görülen en önemli gelişim alanının ise cinsel gelişim olduğu belirtilebilir. Bu gelişim dönemindeki bireylerin cinsel, bedensel ve biyolojik gelişimlerine uyum sağlayabilmesi için ilgili araştırmalar 1şığında uzman desteğine ihtiyaç duyulmaktadır. Bu bağlamda, ergenlerin sağlıklı cinsel yaşam sürdürmeleri ve bu konuda kendilerine ve akranlarına zarar verici deneyimler yaşamalarının önlenebilmesi için konu ile ilgili araştırmaların yapılmasına ihtiyaç olduğu düşünülmektedir. Alanyazında ergen cinselliği ile ilgili olan çalışmaların istenmeyen hamilelik, AIDS, cinsel yolla bulaşan hastalıklar ve riskler üzerinde odaklandığı görülmektedir (Abbott ve Dalla, 2008). Bilinçsiz cinsel ilişkiler sonucunda bu tür istenmeyen sonuçların önlenebilmesi için kaçınma eğitim programlarının; gençler arasında sağlıklı davranışları teşvik etmek ve ergen cinsel faaliyetlerini azaltmak açısından oldukça öneme sahip olduğu belirtilmektedir (Barnett ve Parkhurst, 2005; Harper, Henderson, Schalet, Becker, Stratton ve Raine, 2010; Hulton, 2000). Dolayısıyla ergenler için cinsel kaçınmanın teşvik edilebilmesi için öncelikle cinsel kaçınma ve ilişkili araştırmaların yapılmasına ihtiyaç olduğu düşünülmektedir.

Cinsel kaçınmada öz-yeterliliğin açıklanabilmesi için öncelikle cinsel kaçınmanın ve özyeterliliğin açıklaması gerekmektedir. Sawyer (2007) cinsel kaçınmayı gönüllü olarak cinsel ilişkide bulunmaktan kaçınma olarak tanımlamaktadır. Goodson, Suther, Pruitt ve Wilson, (2003) bazı insanların inançlarına ve ahlaki tutumlarına göre öpüşmemenin ve dokunmamanın da cinsel kaçınma olduğunu belirtmektedirler. Diğer bir bakış açısına göre ise cinsel kaçınma, gençlerin istenmeyen cinsel faaliyetlerini engelleyebilmesi şeklinde tanımlanmıştır (Koffi, 2010). Planes ve diğerleri (2009) tarafından cinsel kaçınmanın ne olduğunu tanımlayabilmek için üniversite öğrencileri üzerinde yapılan bir araştırmada, üniversite öğrencilerinin cinsel kaçınmayı cinsel ilişkiye girmeme, oral seks ve anal seks yapmama olarak tanımladıkları görülmüştür. Ayrıca, mastürbasyon yapmama, fiziksel temasta bulunmama, cinsel ilişkiden doyum almama ve cinsel ilişki ile ilgili egzersizler yapmama gibi cinsel kaçınma ile ilgili hatalı tanımlamalar da yaptıkları bulunmuştur. Barnett ve Parkhurst, (2005) de cinsel kaçınmanın cinsel yolla bulaşan hastalıklara sebep olan cinsel ilişkilerden uzak durma olduğunu belirtmektedir. Horan, Phillips ve Hagan, (1998) yaptıkları araştırmada üniversite öğrencilerinin oral seks ve anal seks'in de cinsel kaçınma olduğuna yönelik mantık dış1 inançlarının olduğu sonucunu elde etmişlerdir. Öz-yeterlilik ise insanların nasıl hissedeceğini, düşüneceğini, motive olacağını ve davranacağını belirleyen ve yeteneklerini yaşamlarını etkileyen olaylarda kullanabilmedeki gösterdikleri performans düzeylerini etkileyen inançları olduğu belirtilmektedir (Bandura, 1994). Ayrıca öz-yeterliliğin bireyin motivasyonu üzerindeki kontrolünü de yönlendirebileceğine ilişkin inancı olduğu şeklinde de ifade edilmektedir (Bandura, 1991). Hulton, (2000) cinsel kaçınmada öz-yeterliliği; kişinin birçok cazip durum karşısında cinsel ilişkiye girmeme konusunda kendine olan güven düzeyi olarak tanımlamaktadır.

Alanyazın incelendiğinde ergenlere yönelik cinsel kaçınma ile ilgili araştırmaların yurt içinde olmadığı, yurt dışında ise sınırlı sayıda olduğu görülmektedir. Diğer taraftan ABD gibi bazı gelişmiş ülkelerde ergenler için cinsel kaçınma eğitim programları yapılmaktadır. Bireylere 
cinsel kaçınmayı öğretmenin ergen gebeliğini ve cinsel yolla bulaşan hastalıkları önlemenin tek yolu olduğu da belirtilmektedir (Harper ve diğerleri, 2010; Kohler, Manhart ve Lafferty, 2008; Lindberg, 2006; Santelli ve diğerleri 2006; Underhill, Montgomery ve Operario, 2008). Ayrıca, Rector (2005) cinsel kaçınmanın akademik kapasiteye doğrudan katkısı olduğunu, bireylerin enerjilerinin ve ilgilerinin büyük bölümünün cinsel faaliyete ayrılması durumunda akademik performans dürtüsünün düştügünü belirtmektedir. Bu çerçevede bireylere cinsel kaçınmayı ögretmenin ergen gebeliği ve cinsel yolla bulaşan hastalıkların önlenebilmesinin yanında bireylerin eğitim-öğretim çağının büyük bir bölümünü geçirdikleri, gelecek yaşantılarını büyük ölçüde etkileyecek olan sınavlara girdikleri bu gelişim döneminde akademik başarılarının da arttırılabilmesi açısından önemli olduğu düşünülebilir. Harper ve diğerleri (2010) tarafından psikolojik danışma hizmetinin cinsel kaçınma üzerindeki etkisini araştırdıkları araştırmada, araştırmaya katılan bireylerde psikolojik danışma çalışmasının cinsel kaçınma yönünde olumlu etkilerinin olduğu sonucuna ulaşılmıştır. Ülkemizde de bu konuda araştırmaların yapılabilmesi için konu ile ilgili değiş̧kenlerin ölçülebileceği ölçme araçlarına ihtiyaç olduğu görülmektedir. Bu nedenle bu araştırmada Hulton, (2000) tarafından geliştirilen ergenler için cinsel kaçınmada öz-yeterlilik ölçeğinin geçerlilik ve güvenirlik analizleri yapılarak Türkçeye uyarlanmaya çalışılmıştır.

\section{YÖNTEM}

\section{Çalışma Grubu}

$\mathrm{Bu}$ araştırmanın çalışma grubu İstanbul'un Sultangazi ilçesindeki ilköğrietim okullarında 8. sınıf düzeyinde öğrenim gören ve bu sınıflarda araştırmaya katılmak isteyen öğrencilerden oluşmaktadır. Araştırmaya katılan 365 öğrencinin 179'i (\%49) kızdır.

\section{İşlem}

Cinsel Kaçınmada Öz-Yeterlilik Ölçeği'nin uyarlama çalışması için ölçeği geliştiren Linda J. Hulton ile e-mail yoluyla iletişim kurulmuş ve ölçeğin uyarlanabileceğine ilişkin gerekli izin alınmıştır. Ölçek, Türkçeye uyarlanma sürecinde İngiliz dilini iyi bilen 4 uzman tarafından Türkçeye çevrilmiş ve daha sonra bu Türkçe formlar tekrar İngilizceye çevrilerek iki form arasındaki tutarlılık incelenmiştir. Yine aynı uzman bireyler elde ettikleri Türkçe formlar üzerinde tartışarak anlam ve dilbilgisi açısından gerekli düzeltmeleri yapmış ve denemelik Türkçe form elde edilmiştir. Bir sonraki aşamada denemelik Türkçe form 46 ögrenciye uygulanmış ve net olmayan ifadeleri belirlemeleri istenmiştir. $\mathrm{Bu}$ uygulama sonucunda öğrencilerin yarıdan fazlasının anlaşılır olmadığını düşündüğü iki madde farklı biçimde ifadelendirilmiştir. Son aşamada bu form, psikolojik danışma ve rehberlik ve ölçme ve değerlendirme alanındaki 4 uzman bireye inceletilerek görüşleri doğrultusunda bazı değişiklikler yapılmıştır.

Ölçeğin kapsam geçerliği için uzman görüşüne başvurulmuş, yapı geçerliği için de Açımlayıcı ve Doğrulayıcı Faktör Analizi yapılmıştır. Şimşek (2007) de teori ile "gerçeğin" birbirinden hangi noktalarda ayrıldığının anlaşılabilmesi için, yapı geçerliği kapsamında yapılan açımlayıcı faktör analizi ile belirlenmiş olan faktör yapılarının doğrulayıcı faktör analizine tabi tutulabileceğini belirtmektedir. Bu çerçevede açımlayıcı faktör analizi ile elde edilen yapının doğrulanması için doğrulayıcı faktör analizi yapılmıştır. Ölçeğin güvenilirliğini belirlemek için ise Cronbach Alfa güvenirlik katsayısı, düzeltilmiş madde-ttoplam korelasyonu ve testin toplam puanlarına göre oluşturulan alt $\% 27$ ve üst $\% 27$ 'lik grupların madde ortalama 
puanları arasındaki farkların sınanması için ilişkisiz t-testi kullanılmıştır. Geçerlik ve güvenirlik analizleri için SPSS 11.5 ve LISREL 8.51 (Jöreskog \& Sörbom, 2001) programları kullanılmıştır.

\section{BULGULAR}

\section{Yapı Geçerliği}

Ölçeğin geliştirilmesi sürecinde öz-yeterlik ile ilgili literatür incelenmiş ve alkol kullanımı, kilo kontrolü ve sigarayı bırakma ile ilgili öz-yeterlik ölçeklerinden faydalanılarak madde havuzu oluşturulmuştur. Daha sonra yapılan açımlayıcı faktör analizi sonucu ölçeğin orijinal versiyonu 9 maddeli tek faktörlü bir yapıya sahip olduğu ve ölçekte yer alan maddelerin faktör yüklerinin 65 ile 84 arasında değisstiği görülmüştür (Hulton, 2000). Bu araştırmada ölçeğin Türkçe formunun faktör yapısının, orijinal formunun faktör yapısı ile tutarlılık gösterip göstermediği açımlayıcı ve doğrulayıcı faktör analizi ile incelenmiştir.

Açımlayıcı faktör analizi (AFA). Cinsel Kaçınmada Öz-yeterlilik Ölçeği'nin yapı geçerliğini incelemek için yapılan AFA'da öncelikle bütün maddeler arasında korelasyon matrisi (gözlenen ve üretilmiş korelasyon matrislerinin arasındaki fark) incelenerek önemli oranda manidar korelasyonların olup olmadığına bakılmış ve faktör analizinin yapılabilmesine uygunluk gösterir nitelikte manidar ilişkilerin olduğu görülmüştür. Ölçeğin yapı geçerliğini belirlemek için yapılan açımlayıcı faktör analizine verilerin uygun olup olmadığını tespit etmek için KMO değerinin .60'dan yüksek ve Barlett testi sonucunun anlamlı çıkması gerektiği belirtilmektedir (Büyüköztürk, 2010). Bu amaçla yapılan analiz sonucunda KMO örneklem uygunluk katsayıs1 .92, Barlett Sphericity testi $\chi^{2}$ değeri ise $1929,42(\mathrm{p}<.001)$ bulunmuş ve ölçek maddelerine verilen cevapların faktörlenebileceği görülmüştür. Araştırmada yapılan ilk analizde faktör özdeğeri 5,33'ün üzerinde olan ve toplam varyansın \%59.27'sini açıklayan tek faktör ortaya çıkmıştır. Ayrıca ölçeğin faktör yüklerinin .53 ile .86 arasında değiştiği bulunmuştur. Açımlayıcı faktör analizi sonucu incelendiğinde ölçeğin Türkçe versiyonunun faktör yapısının orijinal formu ile benzerlik gösterdiği ve her bir maddenin faktör yükünün her iki formada da birbirine yakın olduğu görülmektedir. Ölçeğin Türkçe ve İngilizce versiyonunda yer alan her bir maddenin faktör yükleri Tablo 1'de verilmiştir.

Tablo 1

$$
\text { Açımlayıcı Faktör Analizi }
$$

\begin{tabular}{|c|c|c|}
\hline \multirow{3}{*}{ Maddeler } & \multicolumn{2}{|c|}{ Faktör yükleri } \\
\hline & Türkçe & İngilizce \\
\hline & Versiyonu & Versiyonu \\
\hline $\begin{array}{l}\text { 1. Tahrik olduğun zamanlarda bile kız/erkek arkadaşınla cinsel } \\
\text { ilişkiye girmeye hayır diyebilirsin. }\end{array}$ & .86 & 84 \\
\hline $\begin{array}{l}\text { 2. Cinsel ilişkiye girmeme kararına sonuna kadar bağlı } \\
\text { kalabilirsin. }\end{array}$ & .83 & 81 \\
\hline 3. Cinsel ilişkiye girmeye kesinlikle hayır diyebilirsin. & .82 & 81 \\
\hline $\begin{array}{l}\text { 4. Hayır dediğin zaman kı/erkek arkadaşının üzüleceğini bilsen } \\
\text { bile onunla cinsel ilişkiye girmemeye direnirsin. }\end{array}$ & .82 & 81 \\
\hline $\begin{array}{l}\text { 5. Eğer arkadaşların cinsel ilişkiye girmende mahsur görmezse } \\
\text { bile kız/erkek arkadaşınla cinsel ilişkiye girmemeye direnirsin. }\end{array}$ & .81 & 80 \\
\hline
\end{tabular}


6. Eğer kı/erkek arkadaşın cinsel ilişkiye girmen için baskı yaparsa cinsel ilişkiye girmeme sebeplerini ona açıklayabilirsin.

$\begin{array}{ll}\text { 7. Eğer kı/erkek arkadaşın cinsel ilişkiye girmen için baskı } & .70\end{array}$ 70 yapmaya devam ederse onunla görüşmeyi bitirebilirsin.

8. Cinsel ilişkiye girmeye yol açacak durumlardan kaçınırsın

.64

(yatak odasına gitmek, alkol almak, uyuşturucu kullanmak vs.).

9. Cinsel ilişkiye girmeme konusundaki kararını kı/erkek .53 arkadaşınla konuşabilirsin.

Özdeğer (Eigenvalue)

Açıklanan Varyans (\%)

5,33

Cronbach Alfa $(\alpha)$

Doğrulayıcı faktör analizi (DFA). Cinsel Kaçınmada Öz-yeterlilik Ölçeği’nin yapı geçerliği için ölçeğin orijinal versiyonunun psikometrik özelliklerinin incelendiği çalışmada açımlayıcı faktör analizi sonucu elde edilen tek faktörlü yapının doğrulanması amacıyla DFA uygulanmıştır. Yapılan DFA'da elde edilen modelin uyum indeksleri incelenmiş ve Ki-kare değeri $(\chi 2=92,34 N=365, S D=26, p=0.00)$ ile uyum indeksi değerlerinin (RMSEA $=.084$, $\mathrm{AGFI}=.91, \mathrm{NFI}=.95, \mathrm{CFI}=.97, \mathrm{IFI}=.97, \mathrm{RFI}=.94, \mathrm{GFI}=.95$ ve $\mathrm{SRMR}=.038) \mathrm{kabul}$ edilebilir düzeyde olduğu bulunmuştur. Modele ilişkin faktör yükleri Şekil 1'de gösterilmiştir.

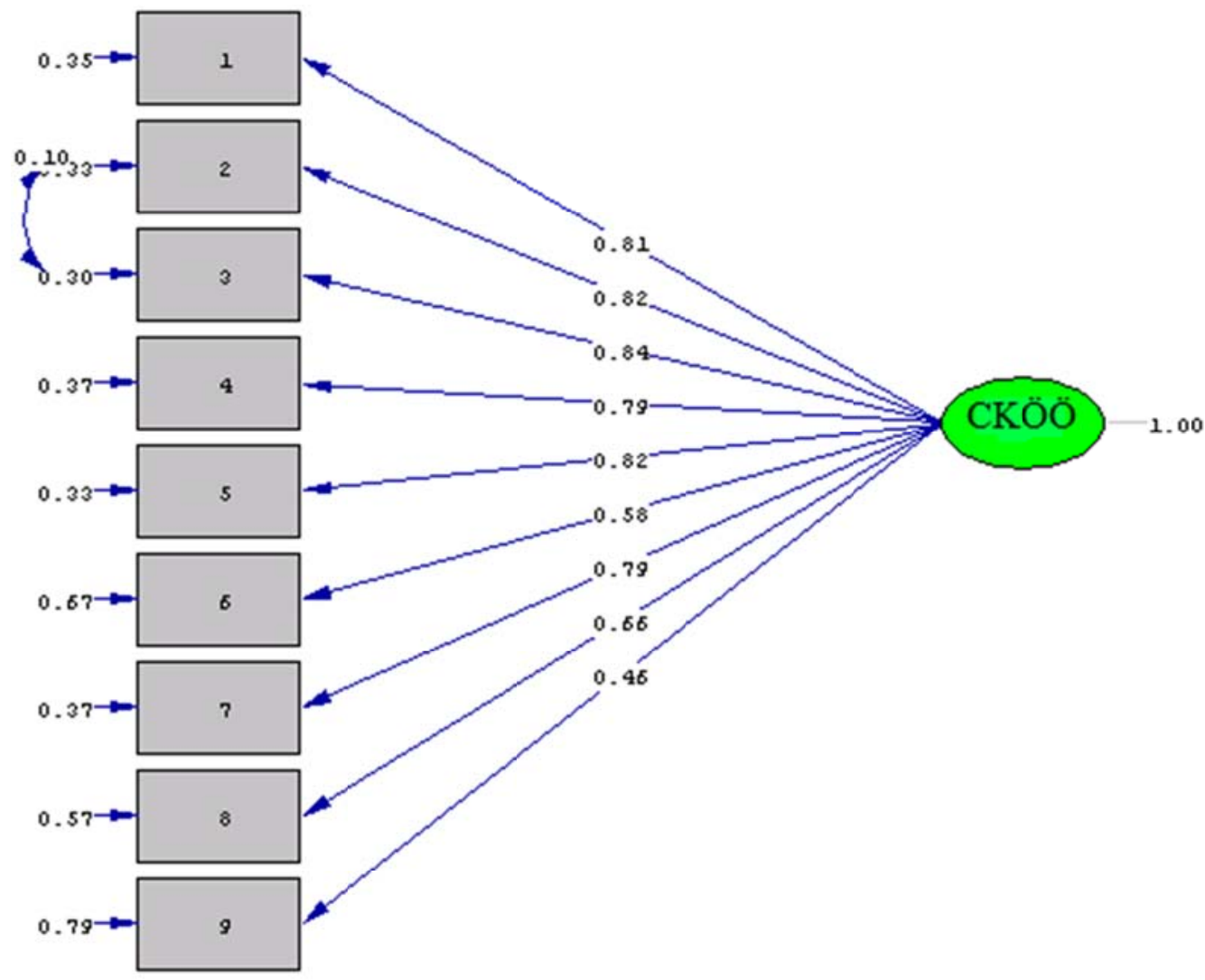

Ki-kare $=92.34, \mathrm{sd}=26, \mathrm{P}$-değeri $=0.00000, \mathrm{RMSEA}=0.084$

Şekil 1. Cinsel Kaçınmada Öz-yeterlilik Ölçeği’ne (CKÖÖ) İlişkin Path Diagramı ve Faktör Yükleri 
Schermelleh-Engel, Moosbrugger ve Müller'e göre (2003) doğrulayıcı faktör analizi sonucu elde edilen uyum indekslerinin; $\chi 2 / \mathrm{sd}$ için $=0 \leq \chi^{2} / \mathrm{sd} \leq 3$, $\mathrm{p}$ değeri için $=0.01 \leq \mathrm{p} \leq 0.05$ arasında, RMSEA için= $0.05 \leq$ RMSEA $\leq 0.08$, AGFI için $=0.90 \leq$ AGFI $\leq 1.00$, GFI için $=95 \leq \mathrm{GFI} \leq 1.00$ ve $\mathrm{SRMR}$ için= $0.02 \leq \mathrm{SRMR} \leq 0.10$ aralığında olması modelin kabul edilebilir olduğunu göstermektedir. Bu bağlamda bu araştırmada elde edilen uyum indeksi değerleri dikkate alındığında cinsel kaçınmada öz-yeterliğe ilişsin modelin iyi uyum verdiği söylenebilir.

\section{Güvenirlik}

Ölçeğin güvenirliğini belirlemek için Cronbach alfa formülü kullanılmıştır. Hulton (2000) tarafından, ölçeğin geliştirilmesi ve psikometrik özelliklerinin incelenmesi amacıyla yapılan çalışmada, ölçeğin Cronbach Alfa katsayısı .91 olarak bulunmuştur. Bu araştırmada da ölçeğin Cronbach Alfa katsayısı $\alpha=.91$ olarak bulunmuştur. Araştırmalarda kullanılabilecek ölçme araçları için öngörülen güvenirlik düzeyinin .60 ve üzeri olduğu (Büyüköztürk, 2010) dikkate alınırsa, ölçeğin güvenirlik düzeyinin yüksek olduğu söylenebilir.

\section{Madde Analizi}

Ölçeğin madde analizi için t-testi ve Düzeltilmiş madde-test korelasyonu sonuçları değerlendirilmiştir. Yapılan analiz sonucu ölçeğin düzeltilmiş madde-test korelasyonlarının .46 ile .79 arasında değiştiği, t-testi sonuçlarının ise ise $15.04(p<.001)$ ile $34.30(p<.001)$ arasında sıralandığı görülmüştür. Madde analizine ilişkin elde edilen bu sonuçlar ölçeğin maddelerinin ayırt edici özelliğe sahip olduğunu göstermektedir. Bulgular Tablo 2'te gösterilmiştir.

\section{Tablo 2}

\begin{tabular}{lll} 
Madde Analizi Sonuçlarl & & \\
\hline Maddeler & $r_{j x}$ & T-testi \\
\hline 1 & .76 & $34,30 * * *$ \\
2 & .76 & $28,60 * * *$ \\
3 & .79 & $30,59 * * *$ \\
4 & .74 & $22,79 * * *$ \\
5 & .75 & $28,10 * * *$ \\
6 & .57 & $20,54 * * *$ \\
7 & .75 & $31,22 * * *$ \\
8 & .62 & $16,46 * * *$ \\
9 & .46 & $15,04 * * *$
\end{tabular}

\section{TARTIŞMA ve SONUÇ}

Bu araştırmanın amacı Cinsel Kaçınmada Öz-yeterlilik Ölçeği’ni Türkçeye uyarlamak ve ölçeğin geçerlik ve güvenirlik analizlerini incelemektir. Açımlayıcı faktör analizi sonucunda toplam varyansın \%59'unu açıklayan ölçeğin orijinal yapısına uygun tek faktörlü bir yapı elde edilmiştir. Ölçek geliştirme ve uyarlama çalışmalarında açıklanan varyans oranı için \%30 ve üzeri ölçüt olarak alındığı düşünüldügünde (Büyüköztürk, 2004), ölçeğin yapı geçerliğinin sağlandığı görülmektedir. Bu tek faktör altında yer alan 9 maddenin faktör yükleri .53'ün üzerinde olduğu için faktör analizi sonucunda ölçekten hiçbir madde atılmamıştır. Ayrıca doğrulayıcı faktör analizi için uyum indeksi sınırları göz önüne alındığında modelin iyi 
düzeyde uyum verdiği ve ölçeğin orijinal faktör yapısının Türkçe versiyonunun faktör yapısıyla uyuştuğu görülmektedir.

Ölçeğin güvenirliği için yapılan analizlere göre iç tutarlılık, testi yarılama, madde toplam korelasyonu ve t-testi sonuçlarının yüksek ve anlamlı bulunması ölçeğin güvenilir bir ölçek olduğunu göstermektedir. Araştırmalarda kullanılabilecek ölçme araçları için öngörülen güvenirlik düzeyinin .60 olduğu (Büyüköztürk, 2010) dikkate alınırsa, ölçeğin güvenirlik düzeyinin yüksek olduğu söylenebilir. Ölçeğin madde analizi için incelenen madde-test korelasyonu sonucu elde edilen korelasyon katsayıs1 .30 ve daha yüksek olan maddelerin bireyleri ölçülen özellik bakımından iyi derecede ayırt ettiği (Büyüköztürk, 2004) göz önüne alındığında, madde-test korelasyonlarının yeterli düzeyde olduğu görülmektedir. \%27'lik alt ve üst grup puanları arasında yapılan t testi sonuçları tüm maddeler için anlamlı bir farklılık olduğunu ortaya koymuştur. Cinsel Kaçınmada Öz-yeterlilik Ölçeği'nin Türkçe formunun geçerlik ve güvenirlik çalışmalarından elde edilen tüm bulgulara göre, bu ölçeğin bireylerin Cinsel Kaçınmada Öz-yeterlilik düzeylerini değerlendirmek amacıyla geçerli ve güvenilir biçimde kullanılabileceği söylenebilir.

Cinsel Kaçınmada Öz-yeterlilik Ölçeği’nin geçerlik ve güvenirlik çalışmallarından elde edilen bulgular çerçevesinde bazı önerilerde bulunulabilir. Ölçeğin geçerlik ve güvenirlik çalışmalarının yürütüldüğü araştırma grubu ilköğretim 8. sınıf öğrencilerinden oluşmaktadır. Dolayısıyla ölçeğin geçerlik ve güvenirliği için farklı yaş gurubundaki ergenlerin yer aldığı örneklemler üzerinde yapılacak çalışmalar da son derece önemlidir. Ergenlerin cinsel kaçınmada öz-yeterlik düzeylerinin arttırılması ve ergenlere cinsel ilişki sırasında korunma yöntemlerinin öğretilmesi, erken gebeliklerin önlenmesi ve cinsel yolla bulaşan hastalıklardan korunma gibi bir takım sorunlarla baş edilmesini kolaylaştırabilir. Ayrıca, konu ile ilgili diğer değişkenlerin araştırıldığ değerlendirilerek kullanılması ve bu araştırmada elde edilen sonuçlarla karşılaştırılması da ölçeğin daha geçerli ve güvenilir bir ölçme aracı olma özeliğini geliştirebilir. Son olarak bu ölçeğin kullanılacağı araştırmaların yapılması ölçeğin ölçme gücüne önemli katkılar sağlayacaktır. 


\section{REFERENCES}

- Abbott, D. A., \& Dalla, R. L. (2008). 'It's a choice, simple as that': Youth reasoning for sexual abstinence or activity. Journal of Youth Studies, 11(6), 629-649.

- Bandura, A. (1991). Self-efficacy mechanism in physiological activation and healthpromoting behavior. In J. Madden, IV (Ed.), Neurobiology of learning, emotion and affect (pp. 229- 270). New York: Raven.

- Bandura, A. (1994). Self-efficacy. In V. S. Ramachaudran (Ed.), Encyclopedia of human behavior (Vol. 4, pp. 71-81). New York: AcademicPress. (Reprinted in H. Friedman [Ed.], Encyclopedia of mentalhealth. San Diego: Academic Press, 1998).

- Barnett, T., \& Parkhurst, J. (2005). HIV/AIDS: Sex, abstinence, and behaviour change. The Lancet, 5, 590-593.

- Büyüköztürk, Ş. (2004). Veri analizi el kitabı. Ankara: Pegem A Yayıncılık.

- Büyüköztürk, Ş. (2010). Sosyal bilimler için veri analizi el kitabı. Ankara: PegemA Akademi Yayınevi.

- Çokluk, Ö., Şekercioğlu, G. ve Büyüköztürk, Ş. (2010). Sosyal bilimler için çok değişkenli istatistik SPSS ve LISREL uygulamaları. Ankara: PegemA Akademi Yayınevi.

- Goodson, P., Suther, S., Pruitt, B. E., \& Wilson, K. (2003). Defining abstinence: Views of directors, instructors, and participants in abstinence-only-until-marriage programs in Texas. The Journal of School Health, 73(3), 91-96.

- Harper, C. C., Henderson, J. T., Schalet, A., Becker, D., Stratton, L., \& Raine, T. R., (2010). Abstinence and teenagers: Prevention counseling practices of health care providers serving high-risk patients in the united states, Perspectives on Sexual and Reproductive Health, 42(2), 125-132.

- Horan, P., Phillips, J., \& Hagan, N. (1998). The meaning of abstinence for college students. Journal of HIV/AIDS Prevention \& Education for Adolescents \& Children, 2(2), 51-66.

- Hulton, L. J. (2000). The application of the Trans theoretical Model of Change to adolescent sexual decision-making for abstinence. Unpublished doctoral dissertation. Charlottesville, VA: University of Virginia.

- Jöreskog, K. \& Sörbom, D. (2001). LISREL 8.51. Scientific Software International.

- Koffi, A. K., \& Kawahara, K. (2010). Sexual abstinence behavior among nevermarried youths in a generalized HIV epidemic country: Evidence from the 2005 Cote d'Ivoire AIDS indicator survey. BMC Public Health, 8. doi:10.1186/1471-2458-8-408.

- Kohler, P. K., Manhart, L. E. ve Lafferty, W. E. (2008). Abstinence-only and comprehensive sex education and the initiation of sexual activity and teen pregnancy, Journal of Adolescent Health, 42(2), 344-351.

- Lindberg, L. D. (2006). Santelli, J. S. and Singh, S., Changes in formal sex education: 1995-2002, Perspectives on Sexual and Reproductive Health, 38(4),182-189.

- Planes, M., Gömez, A. B., Gras, E., Sullman, M. J., Font-Mayolas, S., Cunill, M., \& Aymerich, M., (2009). What is abstinence? Definitions and examples of abstinence, to prevent the sexual transmission of the hiv virus, according to Spanish University students. Behaviour Change, 26(3), 168-173.

- Rector, R., \& Johnson, K. A. (August 2005) Teenage sexual abstinence and academic achievement. The Ninth Annual Abstinence Clearinghouse Conference. Washington D. C. 
- Santelli, J., Ott, M. A., Lyon, M., Rogers, J., Summers, D., \& Schleifer, R. (2006). Abstinence and abstinence-only education: a review of U.S. policies and programs, Journal of Adolescent Health, 38(1),72-81.

- Sawyer, R. G., Howard, D. E., Brewster-Jordan, H., Gavin, M., \& Sherman, M. (2007). "We didn't have sex .... did we?" college students' perceptions of abstinence. American Joumal of Health Studies, 22, 46-55.

- Spahi, B. Yurtkoru, E. S., \& Çinko, M. (2008). Sosyal bilimlerde SPSS'le veri analizi. İstanbul: Beta Basım Yayım Dağıtım.

- Şimşek, Ö. F. (2007). Yapısal eşitlik modellemesine giriş temel ilkeler ve LISREL uygulamaları. Ankara: Ekinoks.

- Tezbaşaran, A. A. (1996). Likert tipi ölçek geliştirme kılavuzu. Ankara: Türk Psikologlar Derneği Yayınları.

- Underhill, K., Montgomery, P., \& Operario, D. (2008). Abstinence plus programs for HIV infection prevention in high-income countries. Cochrane Database of Systematic Reviews, Issue 1, No. CD007006. 